\title{
The relationship between serum dipeptidyl peptidase-4 enzyme and nonalcoholic fatty liver disease in diabetic and nondiabetic patients
}

\author{
Alaaeldin A. Dawood ${ }^{\mathrm{a}}$, Yasser El Ghobashy ${ }^{\mathrm{b}}$, Ayman A. Elgamal ${ }^{\mathrm{C}}$
}

Departments of anternal Medicine, ${ }^{b}$ Medical Biochemistry, ${ }^{\mathrm{C}}$ Tropical Medicine, Faculty of Medicine, Menoufia University, Shebin El-Kom, Egypt

Correspondence to Alaaeldin A. Dawood, MD, Department of Internal Medicine, Menoufia University Hospital, Shebin El-Kom 32511,

Egypt. Mob: 01223525385;

e-mail: alaadawood2000@yahoo.com

Received 23 May 2017

Accepted 14 June 2017

The Egyptian Journal of Internal Medicine 2018, 30:49-53

\begin{abstract}
Background
Dipeptidyl peptidase-4 (DPP4) is a membrane-associated peptidase. It has widespread organ distribution throughout the body and exerts pleiotropic effects. The liver expresses DPP4 to a high degree.

Nonalcoholic fatty liver disease (NAFLD) is more prevalent in patients with type 2 diabetes mellitus (T2DM), and is associated with increased mortality rates. Currently, there is no approved pharmacologic agent for the management of NAFLD. We need to discover more agents in the pathogenesis of NAFLD to attack it. Therefore, the aim of this work is to study the relationship between serum DPP4 enzyme and NAFLD in diabetic and nondiabetic patients.

Patients and methods

This study was conducted on 160 patients divided equally into four groups: the control group included healthy participants; the T2DM group included type 2 diabetic patients without NAFLD; the NAFLD group included nondiabetic NAFLD patients; and the T2DM-NAFLD group included T2DM patients with NAFLD. Laboratory investigation included glycosylated hemoglobin, liver enzymes, lipid profile, and serum DPP4 enzyme.

Results

DPP4 was significantly higher in the T2DM-NAFLD group compared with the other three groups, and in the NAFLD group and T2DM group compared with the control group. There was a significant direct correlation between serum DPP4 and BMI, glycosylated hemoglobin, serum cholesterol, triglycerides, and low-density lipoprotein (LDL). There was a significant inverse correlation between serum DPP4 and high-density lipoprotein (HDL).

Conclusion

DPP4 is significantly higher in diabetic patients compared with nondiabetic patients and in NAFLD patients compared with non-NAFLD patients. DPP4 can be proposed as a novel candidate in NAFLD pathogenesis.
\end{abstract}

\section{Keywords:}

diabetes mellitus, dipeptidyl peptidase-4 enzyme, nonalcoholic fatty liver disease

Egypt J Intern Med 30:49-53

(C) 2018 The Egyptian Journal of Internal Medicine

1110-7782

\section{Introduction}

Nonalcoholic fatty liver disease (NAFLD) is a clinicopathological disease encompassing a spectrum of diseases ranging from simple hepatic steatosis to inflammatory nonalcoholic steatohepatitis (NASH) with increasing levels of fibrosis and eventually hepatic cirrhosis. The increase in the incidence of type 2 diabetes mellitus (T2DM) and obesity leads to an increase in the incidence of NAFLD [1]. The pathogenesis of NAFLD has been associated with insulin resistance, diabetes, oxidative stress, and lipotoxicity [2]. Until now, there is no approved treatment for the management of NAFLD [3-6]. Therefore, we need to determine more agents in the pathogenesis of this disease to attack it.

Dipeptidyl peptidase-4 (DPP4) enzyme is a ubiquitous glycoprotein and occurs as a cell-membrane-bound protein found on the surface of epithelial and acinar cells and in endothelial cells, fibroblasts, and lymphocytes $[7,8]$. It is also present in a soluble form known as cell surface antigen CD26 (CD26/DPP4). This soluble form is found in many biological fluids [9]. DPP4 is widely expressed in numerous tissues including endothelial cells in multiple vascular beds, rendering the enzyme highly accessible to peptide substrates circulating through the gut, liver, lung, and kidney. The liver expresses DPP4 in many places as it presents in bile canaliculi, hepatocytes and hepatic stellate cells. This widespread distribution indicates that DPP4 has pleiotropic biological actions [10]. Therefore, the aim of

This is an open access journal, and articles are distributed under the terms of the Creative Commons Attribution-NonCommercial-ShareAlike 4.0 License, which allows others to remix, tweak, and build upon the work non-commercially, as long as appropriate credit is given and the new creations are licensed under the identical terms. 
this work is to study the relationship between serum DPP4 enzyme and NAFLD in diabetic and nondiabetic patients.

\section{Patients and methods}

This study was conducted on 160 patients divided into four groups: the control group included 40 healthy individuals; the T2DM group included 40 type 2 diabetic patients without NAFLD; the NAFLD group included 40 nondiabetic NAFLD patients; and last, the T2DM-NAFLD group included 40 T2DM patients with NAFLD. These patients were collected from the outpatient clinic of the Internal Medicine Department. Members of the study groups were subjected to thorough history taking and clinical examination. Laboratory investigation was performed for all patients and included glycosylated hemoglobin (HbA1c), serum aspartate aminotransferase, alanine aminotransferase (ALT), $\gamma$-glutamyl transferase (GGT), and lipid profile. Serum DPP4 enzyme level was measured by a quantitative sandwich enzyme immunoassay technique using a commercially available kit (Quantikin Human Clusterin Immunoassay; R\&D Systems Inc., Minneapolis, Minnesota, USA) according to the manufacturer's instructions.

NAFLD was diagnosed by ultrasound. All the other possible etiologies of hepatitis were excluded. None of these patients had alcohol-related disease in the history and none of them had alcohol intake.

The study was conducted from March 2016 to December 2016. The protocol of this study was approved by ethical committee of Faculty of Medicine. Written consent was taken from all studied individuals before enrolling in the study.

Exclusion criteria were as follows: viral hepatitis B or $\mathrm{C}$, storage diseases including Wilson's disease, hemochromatosis, and $\alpha-1$ antitrypsin deficiency, autoimmune hepatitis, drug-induced liver disease, type 1 DM, history of malignancies, chronic or acute diseases of the liver, heart, or kidney. Patients treated with metformin, thiazolidinediones, incretinbased therapy, and statin drugs were excluded.

\section{Statistical methodology}

Data were analyzed using Statistical Package for Social Science SPSS software computer program, version 15 (SPSS Inc., Chicago, Illinois, USA). Quantitative data were presented in mean and SD. Qualitative data were presented in frequency and percentage. To compare between groups, we used $\chi^{2}$-test, analysis of variance, and least significant difference. Correlation between two parameters was done using correlation coefficient. Significance level value was $P$ less than or equal to 0.05 .

\section{Results}

There were no significant differences between the four groups as regards age and sex. BMI was significantly higher in the three patient groups compared with the control group.

Liver enzymes were significantly higher in both NAFLD groups compared with T2DM and control groups. Serum cholesterol, LDL, and triglycerides were significantly higher in the three patient groups compared with the control group and HDL was significantly lower in the three patient groups compared with the control groups. HbA1c was significantly higher in both diabetic groups compared with the NAFLD group and the control group (Table 1).

DPPIV was significantly higher in the T2DMNAFLD group compared with the other three groups and in the NAFLD group and T2DM group compared with control group, whereas there was no significant difference between T2DM and NAFLD groups (Table 1).

There was a significant direct correlation between serum DPP4 enzyme and BMI, HbA1c, liver enzymes, serum cholesterol, triglycerides, and LDL. There was a significant inverse correlation between serum DPP4 enzyme and HDL. There was no significant correlation between serum DPP4 enzyme and age (Table 2).

To adjust the confounding factors, the multivariate logistic regression analysis was done, and the results showed that the following factors had a significant association with NAFLD: serum DPP4 enzyme, $\mathrm{HbA1c}$, BMI, serum total cholesterol, and HDL (Table 3).

\section{Discussion}

In the current study, serum DPP4 levels in T2DM patients and T2DM-NAFLD were significantly higher than in normal control and NAFLD group, respectively. In addition, there was a significant direct correlation between serum DPP4 and HbA1c. These results are in agreement with findings by other studies $[11,12]$. In a study using HepG2 cells, DPP4 expression was enhanced by high glucose, but not by high insulin. Therefore, it is 
Table 1 Comparison between the four groups as regards different parameters $(n=40)$

\begin{tabular}{|c|c|c|c|c|c|c|c|}
\hline & $\begin{array}{l}\text { Control group } \\
\text { (mean } \pm \text { SD) }\end{array}$ & $\begin{array}{l}\text { T2DM group } \\
\text { (mean } \pm S D)\end{array}$ & $\begin{array}{l}\text { NAFLD group } \\
\text { (mean } \pm \text { SD) }\end{array}$ & $\begin{array}{c}\text { T2DM- } \\
\text { NAFLD group } \\
\text { (mean } \pm S D)\end{array}$ & $\begin{array}{c}\text { ANOVA } \\
\text { test }\end{array}$ & $P$ value & LSD (Significance) \\
\hline Age (years) & $48.0 \pm 8.9$ & $51.3 \pm 8.7$ & $49.8 \pm 9.1$ & $54.1 \pm 9.4$ & 1.165 & $>0.05$ & - \\
\hline BMI $\left(\mathrm{kg} / \mathrm{m}^{2}\right)$ & $24.1 \pm 2.5$ & $27.9 \pm 3.6$ & $28.3 \pm 4.4$ & $28.1 \pm 5.1$ & 5.108 & $<0.05$ & $\begin{array}{l}\text { Control vs. the other } \\
\text { three groups }\end{array}$ \\
\hline $\operatorname{ALT}(\mathrm{U} / \mathrm{l})$ & $25.81 \pm 5.3$ & $24.6 \pm 4.9$ & $52.4 \pm 12.1$ & $56.1 \pm 11.6$ & 5.718 & $<0.05$ & $\begin{array}{l}\text { Both NAFLD groups } \\
\text { vs. control and T2DM } \\
\text { groups }\end{array}$ \\
\hline AST (U/l) & $26.3 \pm 6.7$ & $26.2 \pm 5.8$ & $35.2 \pm 7.6$ & $38.2 \pm 7.4$ & 6.178 & $<0.05$ & $\begin{array}{l}\text { Both NAFLD groups } \\
\text { vs. control and T2DM } \\
\text { groups }\end{array}$ \\
\hline GGT (U/I) & $23.1 \pm 2.3$ & $28.5 \pm 3.4$ & $88.1 \pm 7.6$ & $95.4 \pm 10.1$ & 6.82 & $<0.05$ & $\begin{array}{l}\text { Both NAFLD groups } \\
\text { vs. control and T2DM } \\
\text { groups }\end{array}$ \\
\hline $\mathrm{HbA1c}(\%)$ & $4.6 \pm 0.9$ & $7.4 \pm 1.2$ & $4.8 \pm 0.7$ & $7.5 \pm 1.1$ & 15.7 & $<0.05$ & $\begin{array}{l}\text { Both T2DM vs. } \\
\text { control and NAFLD } \\
\text { groups }\end{array}$ \\
\hline Serum DPP4 (ng/ml) & $1675.3 \pm 244.8$ & $2908.8 \pm 436.7$ & $2825.1 \pm 399.2$ & $3431.8 \pm 492.3$ & 48.2 & $<0.05$ & $\begin{array}{l}\text { T2DM-NAFLD group } \\
\text { vs. the other three } \\
\text { groups T2DM and } \\
\text { NAFLD groups vs. } \\
\text { control group }\end{array}$ \\
\hline Total cholesterol $(\mathrm{mg} / \mathrm{dl})$ & $168.5 \pm 29.7$ & $192.3 \pm 37.4$ & $202.0 \pm 28.7$ & $205.6 \pm 31.1$ & 9.182 & $<0.05$ & $\begin{array}{l}\text { The three patient } \\
\text { groups vs. the control } \\
\text { group }\end{array}$ \\
\hline Serum TG (mg/dl) & $135.1 \pm 23.7$ & $157.6 \pm 31.5$ & $148.1 \pm 31.2$ & $171.1 \pm 36.4$ & 12.21 & $<0.05$ & $\begin{array}{l}\text { The three patient } \\
\text { groups vs. the control } \\
\text { group }\end{array}$ \\
\hline Serum LDL (mg/dl) & $99.2 \pm 24.8$ & $111.7 \pm 32.2$ & $107.7 \pm 19.1$ & $121.2 \pm 31.4$ & 9.56 & $<0.05$ & $\begin{array}{l}\text { The three patient } \\
\text { groups vs. the control } \\
\text { group }\end{array}$ \\
\hline Serum HDL (mg/dl) & $46.4 \pm 7.9$ & $42.0 \pm 10.4$ & $40.7 \pm 8.7$ & $39.2 \pm 12.6$ & 8.19 & $<0.05$ & $\begin{array}{l}\text { The three patient } \\
\text { groups vs. the control } \\
\text { group }\end{array}$ \\
\hline \multicolumn{8}{|l|}{$\operatorname{Sex}[n(\%)]$} \\
\hline Males & 7 (17.5) & $9(22.5)$ & $8(20)$ & $9(22.5)$ & $\chi^{2}=0.132$ & $>0.05$ & - \\
\hline Females & $33(82.5)$ & 31 (77.5) & $32(80)$ & 31 (77.5) & & & - \\
\hline
\end{tabular}

ALT, alanine aminotransferase; AST, aspartate aminotransferase; DPP4, dipeptidyl peptidase-4; GGT, $\gamma$-glutamyl transferase; HbA1c, glycosylated hemoglobin; HDL, high-density lipoprotein; LDL, low-density lipoprotein; NAFLD, nonalchoholic fatty liver disease; T2DM, type 2 diabetes mellitus; TG, triglycerides.

Table 2 Correlation between serum dipeptidyl peptidase-4 and other parameters in the diabetic patients

\begin{tabular}{lcc}
\hline & \multicolumn{2}{c}{ Serum DPP4 } \\
\cline { 2 - 3 } & $r$ & $P$ \\
\hline Age & 0.218 & $>0.05$ \\
BMI & 0.784 & $<0.05$ \\
HbA1c & 0.709 & $<0.05$ \\
Total cholesterol & 0.655 & $<0.05$ \\
Triglyceride & 0.648 & $<0.05$ \\
LDL & 0.642 & $<0.05$ \\
HDL & -0.601 & $<0.05$ \\
ALT & 0.722 & $<0.05$ \\
AST & 0.745 & $<0.05$ \\
GGT & 0.812 & $<0.05$ \\
\hline ALT, alanine aminotansferase & AST &
\end{tabular}

ALT, alanine aminotransferase; AST, aspartate aminotransferase; DPP4, dipeptidyl peptidase-4; GGT, $\gamma$-glutamyl transferase; $\mathrm{HbA1c}$, glycosylated hemoglobin; HDL, high-density lipoprotein; LDL, low-density lipoprotein.

speculated that hyperglycemia may induce the hepatic DPP4 expression, but insulin may not
Table 3 Multivariate logistic regression analysis of independent variables associated with nonalchoholic fatty liver disease

\begin{tabular}{lcc}
\hline Factors & Odds ratio $(95 \% \mathrm{Cl})$ & $P$ value \\
\hline Serum DPP4 enzyme & $2.52(1.57-4.05)$ & $<0.001$ \\
BMI & $1.79(1.19-2.69)$ & $<0.001$ \\
HbA1c & $3.05(1.46-6.38)$ & $<0.001$ \\
Total cholesterol & $1.04(1.02-1.06)$ & $<0.001$ \\
HDL & $1.63(1.08-2.47)$ & $<0.001$ \\
\hline
\end{tabular}

$\mathrm{Cl}$, confidence interval; DPP4, dipeptidyl peptidase-4; HbA1c, glycosylated hemoglobin; HDL, high-density lipoprotein.

affect the transcription of DPP4 [13]. The in-vitro assays reported that glucose decreases DNA methylation of DPP4 gene. Hypomethylation of this gene enhances glucose-mediated DNA expression and thus increases the release of DPP4 by the liver, which leads to an increase in soluble DPP4. This might lead to metabolic deteriorations including steatosis [14]. 
These results are in contrast to findings by other studies that reported decreased DPP4 levels in diabetic patients. Researchers speculated that these discrepancies in diabetic patients may be because of factors such as diabetes duration, patient age, and blood glucose control. Exposure of the body to high concentration of glucose for long duration promotes biosynthesis of DPP4 as described before $[15,16]$.

In this study, there was a significant direct correlation between serum DPP4 enzymes, BMI, total cholesterol, triglycerides, and LDL, and a significant inverse correlation between serum DPP4 enzyme and HDL. Similarly, other studies have reported that circulating DPP4 correlated with BMI and waist circumference $[15,17]$. It was demonstrated that enlargement of adipocytes enhances the release of DPP4 from fat cells into the circulation [17]. Kanazawa et al. [18] provides evidence that CD26/DPP4 may be useful as a biomarker for increased risk of obesity.

It is suggested that the weight gain early in life is closely linked to changes in hepatic DPP4 expression, which are in turn associated with variation in DPP4 methylation around exon 2. Methylation in exon 2 of human DPP4 has been previously shown to correlate negatively with its expression in visceral adipose tissue of obese women [19]. DPP4 methylation in adipose tissue correlated positively with HDL cholesterol levels in the blood, indicating a role of adipose tissue DPP4 in lipidemia [20].

DPP4 affects lipid metabolism by the inactivation of peptides such as glucagon-like peptide 1 (GLP-1) and neuropeptide Y. DPP4 also affects lipid metabolism directly. Depression of the gene encoding DPP4 directly increases the activity of the peroxisome proliferator-activated receptor- $\alpha$ pathway, which leads to increased lipid oxidation and reduced lipogenesis. These result in prevention of hepatic steatosis [21].

The results of this study showed a good relation between NAFLD and serum DPP4 level. Serum DPP4 level was significantly higher in patients in the T2DM-NAFLD group compared with those in the T2DM group, and in patients in the NAFLD groups compared with those in the control group. It was presumed that in patients with NAFLD the serum DPP4 activity would be increased and, by the dysfunctional enetro-insular axis, it might contribute to the impairment of glucose tolerance and the speedup of metabolic deterioration observed in NAFLD [22].
Another study showed that hepatic DPP4 mRNA expression level in the livers is significantly increased in NAFLD patients compared with healthy individuals. It also showed that serum DPP4 activity and hepatic expression of DPP4 are correlated with hepatic steatosis and grades of NAFLD [23]. Moreover, DPP4-deficient rats show lower levels of hepatic proinflammatory and profibrotic cytokines and reduced hepatic steatosis compared with wild-type rats. These favorable changes in lipid metabolism are independent of glucose metabolism [24].

In the current study, a positive correlation was found among GGT, ALT, and serum DPP4 levels, which supports the finding that an important part of excess serum DPP4 is of hepatic origin. When we analyzed serum DPP4 levels in both NAFLD groups separately (diabetic and nondiabetic) and compared them with the serum DPP4 level of T2DM group and control group, respectively, we concluded that it is the presence of steatosis that has an important impact on the serum DPP4 level and not the hyperglycemia alone. Similarly in other studies, DPP4 activity in serum and liver specimens of NAFLD patients correlates with serum GGT and ALT levels [23,24]. It was found that serum DPP4 level was significantly higher in the NAFLD group than in the control individuals and was correlated with the histopathological grade of liver disease [25]. Furthermore, the intensity of hepatic DPP4 immunostaining was correlated with the level of liver steatosis [23].

Several clinical studies have shown that GLP-1 receptor agonists reduced fat deposition in the liver and improved liver function independently of body weight reduction in type 2 diabetic patients [26,27]. Another study showed that administration of GLP-1 analog directly reduced triglyceride stores compared with control-treated cells in the absence of insulin [28]. These findings suggest that activation of GLP-1 signaling in the liver has beneficial effects on NAFLD and that DPP4 inhibitors may also affect liver function. However, the impact of improving liver function by DPP4 inhibitors still needs further studies.

From the previous, we hypothesize that hepatic DPP4 is involved in the initiation and progression of NAFLD in the following ways: obesity and/or hyperglycemia induce adipose tissue and hepatic DPP4 expressions. An increase in DPP4 levels leads to initiation or progression of steatosis by direct effect and to an increase in degradation of GLP-1, which also causes more hyperglycemia that leads to further enhancement 
of DPP4 expression with further progression of NAFLD.

Therefore, we can conclude that DPP4 is significantly higher in diabetic patients compared with nondiabetic patients and in NAFLD patients compared with nonNAFLD patients, and there is a further increase in its level if both T2DM and NAFLD are present in the same patient. There was a significant direct correlation between DPP4 and BMI, total cholesterol, TG, LDL, and liver enzymes and an inverse correlation with HDL. DPPIV can be proposed as a novel candidate with several potential functions in NAFLD pathogenesis. Further studies are required to examine the physiological role of DPP4 in the NAFLD liver and to determine whether DPP4 may offer a new treatment target to suppress the progression of NAFLD even in nondiabetic patients.

\section{Acknowledgements}

The authors made a significant contribution to this manuscript, and this manuscript has been read and approved by all the authors and all the authors believe that the manuscript represents honest work.

\section{Financial support and sponsorship \\ Nil.}

\section{Conflicts of interest}

There are no conflicts of interest.

\section{References}

1 Jin ZZ, Kelseanna HH, Xing YW, Su JF, Xun LP, Fan DM, et al. Clinical guidelines of non-alcoholic fatty liver disease: a systematic review. World J Gastroenterol 2016; 22:8226-8233.

2 Chalasani N, Younossi Z, Lavine JE, Diehl AM, Brunt EM, Cusi K, et al. The diagnosis and management of non-alcoholic fatty liver disease: practice Guideline by the American Association for the Study of Liver Diseases, American College of Gastroenterology, and the American Gastroenterological Association. Hepatology 2012; 55:2005-2023.

3 Sanyal AJ, Chalasani N, Kowdley KV, McCullough A, Diehl AM, Bass NM, et al. Pioglitazone, vitamin $\mathrm{E}$, or placebo for nonalcoholic steatohepatitis. $\mathrm{N}$ Engl J Med 2010; 362:1675-1685.

4 Loomba R, Lutchman G, Kleiner DE, Ricks M, Feld JJ, Borg BB, et al. Clinical trial: pilot study of metformin for the treatment of non-alcoholic steatohepatitis. Aliment Pharmacol Ther 2009; 29:172-182.

5 Ratziu V, Charlotte F, Bernhardt C, Giral P, Halbron M, Lenaour G, et al. Long-term efficacy of rosiglitazone in nonalcoholic steatohepatitis: results of the fatty liver improvement by rosiglitazone therapy [FLIRT 2] extension trial. Hepatology 2010; 51:445-453.

6 Armstrong MJ, Gaunt P, Aithal GP, Barton D, Hull D, Parker R, et al. Liraglutide safety and efficacy in patients with non-alcoholic steatohepatitis [LEAN]: a multicentre, double-blind, randomised, placebo-controlled phase 2 study. Lancet 2016; 387:679-690.

7 Erin EM, Daniel JD. Pharmacology, physiology, and mechanisms of action of dipeptidyl peptidase-4 inhibitors. Endocr Rev 2014; 35:992-1019.

8 Yazbeck R, Howarth GS, Abbott C. Dipeptidyl peptidase inhibitors, an emerging drug class for inflammatory disease? Trends Pharmacol Sci 2009; 30:600-607.
9 Cordero OJ, Salgado FJ, Nogueira M. On the origin of serum CD26 and its altered concentration in cancer patients. Cancer Immunol Immunother 2009; 58:1723-1747.

10 Kaji K, Yoshiji H, Ikenaka Y, Noguchi R, Aihara Y, Douhara A, et al. Dipeptidyl peptidase-4 inhibitor attenuates hepatic fibrosis via suppression of activated hepatic stellate cell in rats. J Gastroenterol 2014; 49:481-491.

11 Lee SA, Kim YR, Yang EJ, Kwon E-J., Kim SH, Kang SH, et al. CD26/DPP4 levels in peripheral blood and T cells in patients with type 2 diabetes mellitus. J Clin Endocrinol Metab 2013; 98:2553-2561.

12 Radwan HA, Hasniza ZH, Zaid H, Sameer DS, Sekaran M. Serum levels of soluble CD26/dipeptidyl peptidase-IV in type 2 diabetes mellitus and its association with metabolic syndrome and therapy with antidiabetic agents in malaysian subjects. Plos One 2010; 10:e0140618.

13 Yang J, Campitelli J, Hu G. Increase in DPP-IV in the intestine, liver and kidney of the rat treated with high fat diet and streptozotocin. Life Sci 2007; 81:272-279.

14 Baumeier C, Saussenthaler S, Kammel A, Jähnert M, Schlüter L, Hesse D, et al. Hepatic DPP4 DNA-methylation associates with fatty liver. Diabetes 2017; 66:25-35.

15 Fadini GP, Albiero M, Menegazzo L, de Kreutzenberg SV, Avogaro A. The increased dipeptidyl peptidase-4 activity is not counteracted by optimized glucose control in type 2 diabetes, but is lower in metformin-treated patients. Diabetes Obes Metab 2012; 14:518-522.

16 McKillop AM, Duffy NA, Lindsay JR. Decreased dipeptidyl peptidase-IV activity and glucagon-like peptide- 1 amide degradation in type 2 diabetic subjects. Diabetes Res Clin Pract 2008; 79:79-85.

17 Lamers D, Famulla S, Wronkowitz N, Hartwig S, Lehr S, Ouwens DM, et al. Dipeptidyl peptidase 4 is a novel adipokine potentially linking obesity to the metabolic syndrome. Diabetes 2011; 60:1917-1925.

18 Kanazawa I, Tanaka K, Sugimoto T. DPP-4 inhibitors improve liver dysfunction in type 2 diabetes mellitus. Med Sci Monit 2014; 20: 1662-1667.

19 Turcot V, Bouchard L, Faucher G, Tchernof A, Deshaies Y, Perusse L, et al. DPP4 gene DNA methylation in the omentum is associated with its gene expression and plasma lipid profile in severe obesity. Obesity 2011 ; 19:388-395.

20 Turcot V, Tchernof A, Deshaies Y, Pérusse L, Bélisle A, Marceau P, et al. Comparison of the dipeptidyl peptidase- 4 gene methylation levels between severely obese subjects with and without the metabolic syndrome. Diabetol Metab Syndr 2013; 5:4.

21 Minoru I, Takumi K, Eitaro T, Michio S. Dipeptidyl peptidase-4: a key player in chronic liver disease. World J Gastroenterol 2013; 19: 2298-2306.

22 Hanley AJ, Wagenknecht LE, Festa A, D'Agostino RB Jr, Haffner SM. Alanine aminotransferase and directly measured insulin sensitivity in a multiethnic cohort: the Insulin Resistance Atherosclerosis Study. Diabetes Care 2007; 30:1819-1827.

23 Balaban YH, Korkusuz P, Simsek H, Gokcan H, Gedikoglu G, Pinar A, et al. Dipeptidyl peptidase IV [DDP IV] in NASH patients. Ann Hepatol 2007; 6:242-250.

24 Ben-Shlomo S, Zvibel I, Shnell M, Shlomai A, Chepurko E, Halpern Z, et al. Glucagon-like peptide-1 reduces hepatic lipogenesis via activation of AMP-activated protein kinase. J Hepatol 2011; 54:1214-1223.

25 Firneisz G, Varga T, Lengyel G, Fehér J, Ghyczy D, Wichmann B, et al. Serum dipeptidyl peptidase-4 activity in insulin resistant patients with nonalcoholic fatty liver disease: a novel liver disease biomarker. PLoS One 2010; 5:e12226.

26 Cuthbertson DJ, Irwin A, Gardner CJ. Improved glycaemia correlated with liver fat reduction in obese, type 2 diabetes, patients with given glucagon-like peptide-1 [GLP-1] receptor agonists. PLoS One 2012; 7: e50117.

27 Buse JB, Klonoff DC, Nielsen LL. Metabolic effects of two years of exenatide treatment on diabetes, obesity, and hepatic biomarkers in patients with type 2 diabetes: an interim analysis of data from the openlabel, uncontrolled extension of three double-blind, placebo-controlled trials. Clin Ther 2007; 29:139-153.

28 Gupta NA, Mells J, Dunham RM. Glucagon-like peptide-1 receptor is present on human hepatocytes and has a direct role in decreasing hepatic steatosis in vitro by modulating elements of the insulin signaling pathway. Hepatology 2010; 51:1584-1592. 